\title{
A world overview of organic Rankine cycle as waste heat recovery alternative
}

\author{
Una visión mundial del ciclo Rankine orgánico como alternativa de recuperación de calor residual \\ Guillermo Eliecer Valencia-Ochoa ${ }^{1 *}$, Aldair Enrique Benavides-Gamero ${ }^{2}$, Josué Miguel Camargo-Vanegas ${ }^{3}$
I*Doctor en Ingeniería Mecánica, guillermoevalencia@mail.uniatlantico.edu.co, ORCID: 0000-0001-5437-1964, Universidad del Atlántico, Barranquilla, Colombia.
Ingeniero Mecánico, aebenavides@mail.uniatlantico.edu.co, ORCID: 0000-0002-3024-6621,Universidad del Atlántico, Barranquilla, Colombia.
Ingeniero Mecánico, josuecamargovanegas@gmail.com, ORCID: 0000-0002-5284-3822,Universidad del Atlántico, Barranquilla, Colombia.

Cómo citar: G. Valencia-Ochoa, A. Benavides-Gamero and J. Camargo-Vanegas, "A world overview of organic Rankine cycle as waste heat recovery alternative". Respuestas, vol. 24, no. 3, 7-14, 2019.

Received on January 27, 2018 - Approved on June 03, 2018.

\section{ABSTRACT}

\section{Keywords:}

Organic fluid, Industrial engine

ORC,

Waste heat recovery system, World overview
In this work the advantage of the use and implementation of ORC heat recovery systems for low temperature $\left(<230^{\circ} \mathrm{C}\right)$ exhaust gases from a natural gas engine was studied. Different organic fluids and working conditions were analyzed in order to determine the best decision in terms of energy efficiency and exergética refers to criteria such as cost, environmental impact, flammability toxicity among others. It was found that the performance for the different configurations is closely linked to the evaporation pressure, reaching an electrical power of $120 \mathrm{kWe}(10 \%)$ for the simple configuration. The working fluid with the highest performance was acetone regardless of the configuration analyzed. Simultaneously, an international and national context was created in different fields for heat recovery systems.

\section{RESUMEN}

\section{Palabras clave:}

Fluido orgánico, Motor industrial ORC,

Sistemas de recuperación de calor residual, Visión mundial
En este trabajo se estudió la ventaja que posee el uso e implementación de los sistemas de recuperación de calor ORC para los gases de escape a baja temperatura $\left(<230^{\circ} \mathrm{C}\right)$ proveniente de un motor a gas natural. Diferentes fluidos orgánicos y condiciones de trabajo fueron analizados con la finalidad de determinar la mejor decisión en cuanto a eficiencia energética y exergética se refiere teniendo criterios tales como, costos, impacto ambiental, toxicidad flamabilidad entre otros. Se encontró que el rendimiento para las distintas configuraciones está estrechamente ligada a la presión de evaporación, llegando a alcanzar una potencia eléctrica de 120kWe (10\%) para la configuración simple. El fluido de trabajo con mayor desempeño fue la acetona independientemente de la configuración analizada. De manera simultánea se realizó un contexto a nivel internacional y nacional en diferentes ámbitos para los sistemas de recuperación de calor.

\section{Introduction}

Due to the problems generated by the excessive use of non-renewable energy sources in the economic, social, technological and environmental fields, the need for inclusions of new energy alternatives is increasingly denoted. Of the different energy alternatives, the residual heat recovery systems stand out due to the easy adaptation they have when working with the plants currently in use.

Waste heat recovery is a method in which waste heat from a plant is used for cogeneration [1], however the efficiency of these systems depends on the quality of energy waste produced in industry, which is a parameter associated with the temperature of the

*Corresponding author

E-mail address: guillermoevalencia@mail.uniatlantico.edu.co (Guillermo Eliecer Valencia Ochoa)

(c) (1) $\Theta$ Peer review is the responsibility of the Universidad Francisco de Paula Santander

c) This is an article under the license CC BY-ND (http://creativecommons.org/licenses/by-nc-nd/4.0/). 
same. In the case of the exhaust gases of an engine if the temperature is higher than $650^{\circ} \mathrm{C}$ it is considered of high quality [2], for ranges between $230^{\circ} \mathrm{C}$ and $560^{\circ} \mathrm{C}$ they are of intermediate quality [3] and for exhaust gases with a temperature lower than $230^{\circ} \mathrm{C}$ they are considered of low quality [4].

In the last decades the ORC (Organic Rankine Cycle) heat recovery systems have been consolidated as a mature technology, in such a way that it has been standardized as one of the technologies with greater viability as regards the conversion of waste heat to electrical energy [5], [6]. Its high utilization of residual energy, easy reduction of volume and weight, rigidity for different applications, long service life, low price and low maintenance are one of the many advantages that have this cycle, compared to others such as supercritical CO2 and Kalina [7], [8].

Having as a goal the rational use of energy, different authors have proposed and analyzed different applications from the selection of the organic fl uid according to environmental, economic, toxicity, fl ammability among others [7], [9]-[11] for the improvement in the performance of the same, however, when taking into account all these conditions, few are the fl uids to use [12]-[14].

With the development and optimization of CROs applied to engines, we seek to recover waste heat with the goal of producing energy at low cost [15], not forgetting that its use is diversifi ed to power generation in geothermal fi elds [16], hybrids [17], biomass [18], among others. More advanced analyses such as thermo-economics and advanced exergoeconomic analyses have been developed for the ORC [19].

The purpose of this work, is in the characterization of the most infl uential parameters in the exergetic and energetic effi ciency, besides the search of the most effi cient fl uid for the different confi gurations to analyze.

\section{Waste heat recovery system based on ORC}

The chronological evolution of the research work associated with the implementation of ORC for waste energy recovery is shown in Figure 1, which highlights 5 stages clearly identifi ed in the literature.

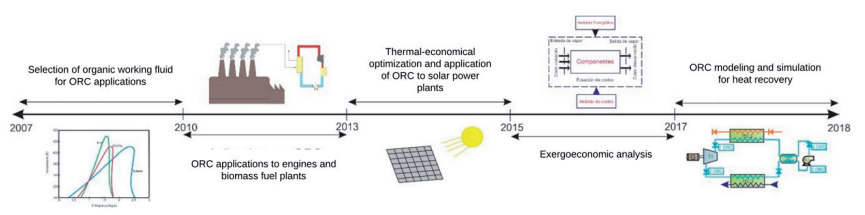

Figure 1. Chronological evolution of research in ORC

The application of different organic fluids in ORC has been of interest to many researchers, because the change of phase from liquid to steam in the system affects its thermal performance. In addition, the thermochemical properties of the fluid must support both thermodynamic stability and the potential environmental impact [20].

In the period from 2007 to 2010, authors such as Drescher et al. [21] conducted research on the application of new working fluids in ORC for a biomass application, and Mago et al. [22] theoretically studied the effect these fluids have on cycle performance at different operating temperatures and pressures. Kosmadakis et al. [23] performed tests on more than 30 organic fluids, in this study it is determined that R245fa is the most suitable for ORC applications with MCI in terms of performance, but in environmental terms its use is restricted by international standards given its global warming potential (GWP) value. In solar applications Tchance et al. [24] determine that the most suitable fluid is the refrigerant $\mathrm{R}-134 \mathrm{a}$, due to its low toxicity and flammability, in addition to the high ratio of pressure and efficiency that can be handled in the ORC when used.

For the period from 2010 to 2013, some contributions were made to the application of ORC to generation plants with biomass and combustion engines, highlighting the work of Vaja and Gambarotta [25], who when evaluating only with an energy and not thermo-economic approach the performance of the simple and regenerative ORC configurations, for the use of waste gas heat from a stationary MCI of $2900 \mathrm{~kW}$, achieve a $12 \%$ increase in the efficiency of the process. The system was evaluated only for a single operating condition of the thermal source, and no economic indicators were studied to determine the viability of the proposed system. Kalina [18], investigated the performance of a biomass power generation system consisting of a gasifier, two gas MCI G3412C LE and G3412C TA of $360 \mathrm{~kW}$ and 
$280 \mathrm{~kW}$ respectively, and an ORC, the latter is used as heat recovery in equipment exhaust manifold and cooling water. The theoretical study lacks experimental results of the thermal source and an economic analysis to prove and guarantee its feasible and viable application in a real context. Also, Mingshan et al [26] performed an energy analysis for the SORC in order to recover energy from a heavy-duty diesel engine, obtaining a heat recovery efficiency between $10 \%$ and $15 \%$ when the plate heat exchanger is optimized, and the engine operates at partial load, with a medium-high power condition instead of the engine's nominal duty point, justifying the study at different engine operating speeds, which requires engine modeling.

Tian et al. [27] then performed a techno-economic analysis of a single ORC coupled to a $235 \mathrm{~kW}$ diesel MCI, to evaluate 20 different working fluids and obtain both the highest net output power per unit of mass flow and the best energy efficiency with refrigerants R-141b and R-123 respectively. The study is limited to a single engine operating condition and a proposal for parametric optimization of the generation cost and evaporator dimensions.

In the period 2013 to 2015 , efforts were focused on developing heat recovery systems with ORC, for solar thermal and geothermal power generation applications, highlighting the work of Hung et al. [28] who investigated the behavior of the simple ORC, only for the recovery of energy from the residual heat of the air produced by solar ventilation systems, consequently the overall efficiency of the system increased by $6.2 \%$. On the other hand, Zare V. [29] began to evaluate economic criteria for thermal performance studies, applied to three ORC configurations associated with binary geothermal power plants, showing better energy results for the $\mathrm{RORC}$, and from the economic point of view the SORC is the best option, given that it consists of the least amount of equipment and a lower acquisition cost. The results are limited only to the geothermal source evaluated and the fluids studied, in addition the study of the double pressure configuration is not presented.
Additionally, studies from the exergetic point of view have been developed in detail without thermoeconomic analysis, such as the modeling developed by Kerme and Orfi [30], who evaluate the influence of temperature at the inlet of an ORC turbine on energy and exergetic efficiency parameters driven by solar collectors, obtaining that the increase in temperature increases efficiency, while the total exergy destruction of the decrease.

In order for an ORC to present optimal operating parameters, it must mainly comply with the criterion of minimum destroyed exergy, the exergetic analysis makes it possible to identify all aspects that affect global energy efficiency, and the accounting of exergoeconomic costs aims to establish a monetary value for all flows of materials and energy, providing a reasonable basis for the allocation of prices, an approach that has predominated in recent studies of application of ORC to recovery of waste gases [31].

In the period from 2015 to 2017, the trend in research concerning exergoeconomic analyses increased in quantity and depth, since they have been based on models such as the work of Karellas and Braimakis [32], by obtaining a thermodynamic model, and an economic analysis of a micro-scale trigeneration system capable of producing combined heat, electricity and refrigeration, based on the joint operation of an ORC and a Steam Compression Cycle (VCC), where the three systems involved, ORC, VCC and the biomass electricity generator, were connected to the same axis, for electricity production equal to $1.42 \mathrm{kWe}$, and a calorific power of $53.5 \mathrm{kWth}$, with a net electrical efficiency of $2.38 \%$, while the energy efficiency of the ORC was estimated at around 7\%. The development of multigeneration energy systems based on geothermal energy has also been optimized with heat recovery cycles, in this sense Akrami et al. [33] include an ORC to generate electricity and heating, performing an energy, exergetic and exergoeconomic analysis of the system to achieve an energy and exergetic efficiency of $34.98 \%$ and $49.17 \%$ respectively.

Studies focused on vehicle engines and not on generation stationary engines have been evaluated by simulations of the performance of a high-strength 
truck equipped with an on-board ORC exhaust heat recovery system, where the truck/engine and ORC/ cooling system models were developed in GT-suite and experimentally validated, complemented by a coupling model in the Simulink environment, and conclude that the speed of the truck engine affects its performance with the ORC system, and that the truck engine shows a gain of $3.07 \mathrm{~kW}$ at the speed of $95 \mathrm{~km} / \mathrm{h}$ under full load conditions [34].

\section{Distribution of ORC facilities in the industry}

Figure 2 shows that ORC applications for the purpose of exploiting low-quality waste heat have been tested in different industrial facilities, where $39 \%$ of the applications are focused on gas turbines, while $16 \%$ are focused on MCI [35], [36].

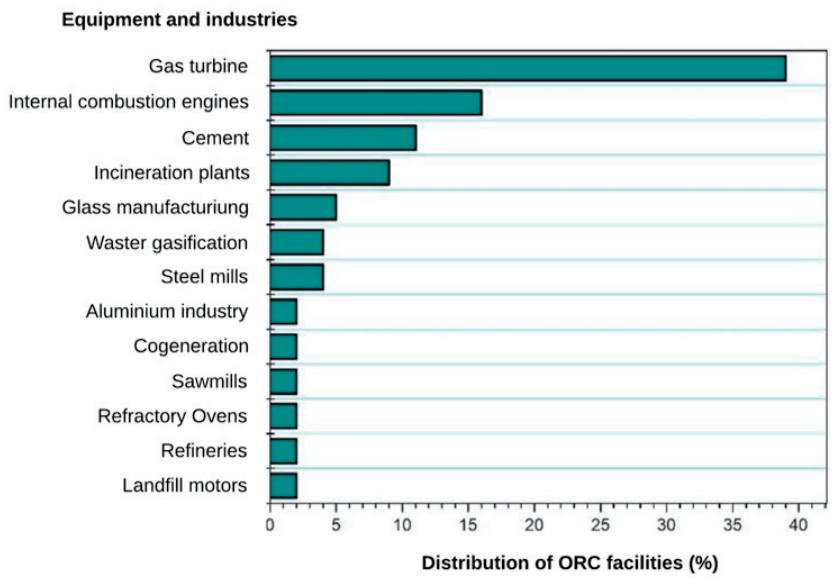

Figure 2. Distribution of ORC facilities in the industry Source: Adapted from [35], [36]

To design a heat recovery cycle is preponderant to know the recovered power, Figure 3 represents the companies that implement more ORC applications and the energy recovered with these systems. The Israeli company ORMAT, able to take advantage of its 1102 ORC units, manages to generate 1701 MW of installed capacity and its worldwide presence is highlighted. By number of units (267) and installed capacity (363 MW) is followed by the Italian company Turboden, presenting a competition in Europe ORC. In addition, the countries with the highest total installed capacity in MWel are presented in blue, with the USA standing out with $80 \mathrm{MWel}$, closely followed by China with $74 \mathrm{MWel}$ and Canada with $70 \mathrm{MWel}$.

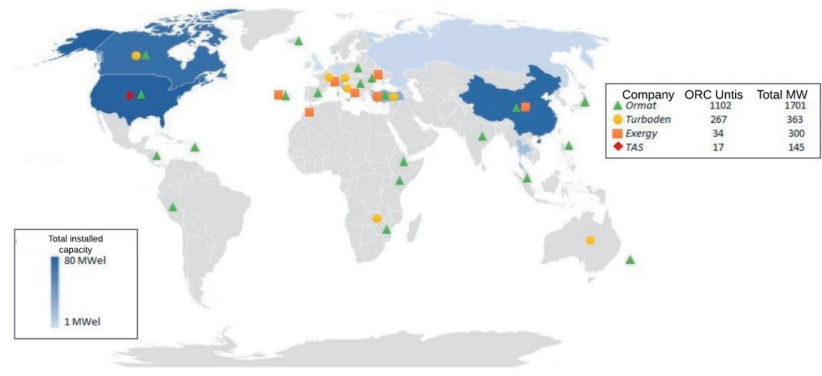

Figure 3. Total installed energy recovery capacity by country Source: Adapted from [35], [36]

\section{Evaluation of ORC performance for waste heat recovery}

The ORC uses organic compounds, i.e. hydrocarbons, refrigerants, ethers and siloxanes, instead of water as the working fl uid; therefore, cycle performance depends on the selection of the working fl uid, which means that each system requires a study under particular operating conditions, as shown in Figure 4.
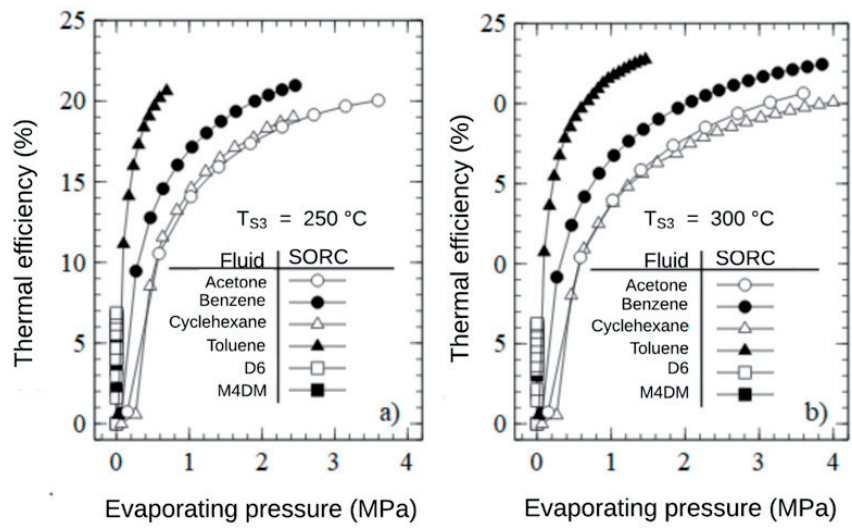

Figure 4. Evaluation of simple ORC with different organic fluids

The simple ORC coupled with a generation motor under a configuration shown in Figure 5, and operating with thermal oil temperatures at the evaporator inlet (TS3 source temperature) ranging from $250^{\circ} \mathrm{C}$ to $300^{\circ} \mathrm{C}$, and turbine and pump efficiencies of 80 $\%$ respectively, can reach electrical power levels close to $120 \mathrm{kWe}$, which would represent a $10 \%$ increase in the power of the Jenbacher JMS 612 GS-N.L motor under study at low operating speed, where it generates around $1200 \mathrm{kWe}$. However, this performance can be improved with thermo-economic optimizations of different ORC configurations for the operating conditions of the exhaust gases of the stationary natural gas generation engine. 


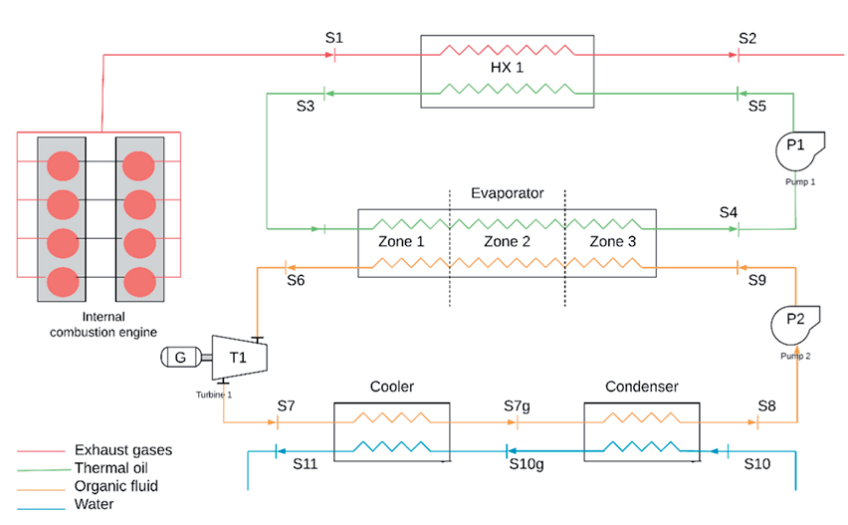

Figure 5. ORC-Secondary Circuit Confi guration of ICE-Coupler

Considering that an ORC generally uses isentropic organic fl uids, with low vaporization heat, do not need to be overheated to increase their recovery effi ciency, subcritical working conditions are desired for lower cost equipment, and favors the economic viability of these projects when used for energy recovery processes for generation purposes [37].

The performance of the different ORC confi gurations in a waste gas recovery system depends primarily on evaporating pressure. The confi guration studied are the simple Organic Rankine cycle (SORC), the dual Organic Rankine cycle (DORC), and the regenerative Organic Rankine cycle (RORC). However, other variables to a lesser extent also affect both the power delivered by the system and the thermal effi ciency of the ORC, as shown in Figure 6 the single ORC cycle, with recuperator and double pressure.
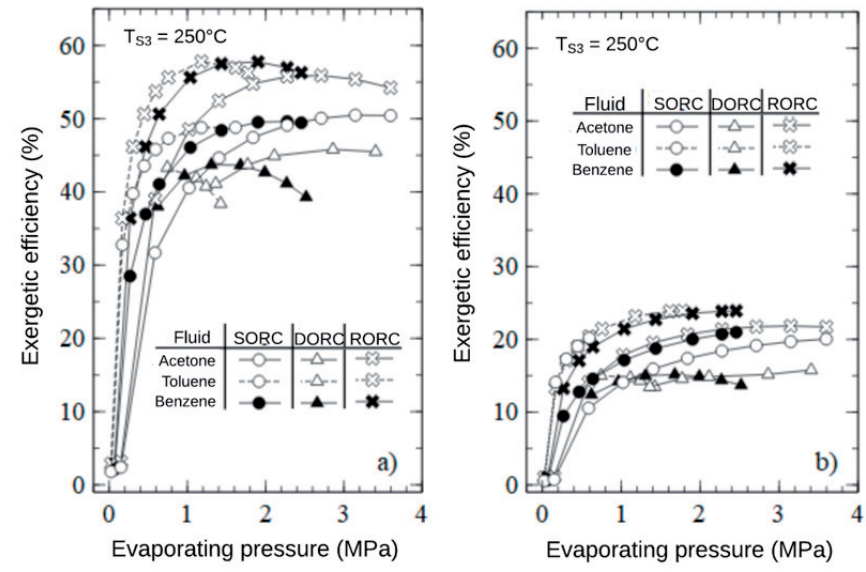

Figure 6 . Thermal and exergetic efficiency of different ORC configurations operating with Acetone, Benzene and Toluene.

These organic fluids have a good performance in the temperature range that can be obtained through the residual gases of the engine, where acetone is the most efficient compound for both study cases.

\section{Conclusions}

Climate change is one of the environmental problems that is orienting researchers to the development of energy generation systems that promote the rational use of energy and a better cost-benefit ratio. In this sense, waste heat recovery systems of generation engines through organic Rankine cycles have been considered as a technology that promises an important market penetration, once the technical and economic barriers are overcome. Even so, there has been an exponential increase in research related to the subject, in addition to the availability of compact ORC equipment available on the market, of which $16 \%$ correspond to recovery of residual heat from MCI.

With respect to the bibliographic review developed on the subject, it has been evidenced that a great part of the works has been based on the theoretical modeling of the phenomenon, which has not allowed to know really the performance and economic indicators of these units when operating coupled the exhaust gases of engines from generation to natural gas. The characterization and validation of the residual heat of the generation engine has been considered as a fundamental factor for the application of the ORC in these real operating environments.

Likewise, it can be concluded that ORC operating with gases at low temperature $\left(<230^{\circ} \mathrm{C}\right)$ is energetic and economically viable, which has allowed its presence in the market since the early 80 's, especially when biomass is used as a resource, geothermal and solar solutions. However, there are still aspects that limit the progress of this technology when integrated with internal combustion engines with exhaust gases at medium temperature $\left(230^{\circ} \mathrm{C}\right.$ to $\left.650^{\circ} \mathrm{C}\right)$, such as the economy of scale of the process, the skepticism of some of the plant managers when integrating a solution with high PBP and LCOE, as well as the neglect of the recovery of residual heat in the engines by governments and decision makers in the industrial sector. These problems particularly to date and hinder the widespread acceptance of ORC technology in industrial generation systems. Thus, this research pursues the thermo-economic optimization of single 
ORC configurations, with recuperator and double pressure integrated to a $2 \mathrm{MW}$ natural gas ICM, in order to improve their economic viability.

\section{References}

[1] T. Koroglu and O. S. Sogut, "Advanced exergoeconomic analysis of organic rankine cycle waste heat recovery system of a marine power plant", International Journal of Thermodynamics, vol. 20, no. 3, pp. 140-151, 2017.

[2] B. Peris, "Thermo-economic assessment of small-scale organic Rankine cycle for lowgrade industrial waste heat recovery based on an experimental application", Universitat Jaume I, no. july, 2017.

[3] J. Alean, F. C. Janna and C. Gomez, et al. "Recuperación de energía en procesos industriales", Universidad Nacional de Colombia, no. november, 2015. ISBN: 978958-775-502-2

[4] H. Zhang, X. Guan, Y. Ding and C. Liu, "Emergy analysis of Organic Rankine Cycle (ORC) for waste heat power generation", Journal of Cleaner Production, vol. 183, pp. 1207-1215, 2018.

[5] S. Lecompte, H. Huisseune, M. Van Den Broek, B. Vanslambrouck and M. De Paepe, "Review of organic Rankine cycle (ORC) architectures for waste heat recovery", Renewable and Sustainable Energy Reviews, vol. 47, pp. 448461, 2015.

[6] S. Lecompte, A. Oyeniyi, N. Christos, M. Lazova, A. Kaya, M. Van den Broek and M. De Paepe, "Case Study of an Organic Rankine Cycle (ORC) for Waste Heat Recovery from an Electric Arc Furnace (EAF)", Energies, MDPI, Open Access Journal, vol. 10, no. 5, pp. 1-16, 2017.

[7] E. H. Wang, H. G. Zhang, B. Y. Fan, M. G. Ouyang, Y. Zhao and Q. H. Mu, "Study of working fluid selection of organic Rankine cycle (ORC) for engine waste heat recovery", Energy, vol. 36, no. 5, pp. 3406-3418, 2011.
[8] S. Goel, et al., "MARKET POTENTIAL STUDY FOR ORGANIC RANKINE CYCLE TECHNOLOGY IN INDIA A Publication on Industrial Energy Efficiency BUREAU OF ENERGY EFFICIENCY", Indo-German Energy Forum, 2014.

[9] P. Liu, G. Shu, T. Hua and X. Wang, "Engine Load Effects on the Energy and Exergy Performance of a Medium Cycle/Organic Rankine Cycle for Exhaust Waste Heat Recovery", Entropy, vol. 20, no. 2, pp. 137, 2018.

[10] H. Tian, G. Shu, H. Wei, X. Liang and L. Liu, "Fluids and parameters optimization for the organic Rankine cycles (ORCs) used in exhaust heat recovery of Internal Combustion Engine (ICE)", Energy, vol. 47, no. 1, pp. 125-136, 2012.

[11] M. Tavano, et al., "Thermodynamic Optimization of heat recovery ORCs for heavy Thermodynamic Optimization of pure heat recovery ORCs for mixtures heavy duty Internal Combustion Engine: fluids vs zeotropic duty Internal Combustion Engine: pure", Energy Procedia, vol. 129, pp. 168-175, 2017.

[12] F. Vélez, J. J. Segovia, M. C. Martín, G. Antolín, F. Chejne and A. Quijano, "A technical, economical and market review of organic Rankine cycles for the conversion of low-grade heat for power generation", Renewable and Sustainable Energy Reviews, vol. 16, no. 6, pp. 4175-4189, 2012.

[13] B. Saleh, G. Koglbauer, M. Wendland and J. Fischer, "Working fluids for low-temperature organic Rankine cycles", Energy, vol. 32, no. 7, pp. 1210-1221, 2007.

[14] B. F. Tchanche, G. Papadakis, G. Lambrinos and A. Frangoudakis, "Fluid selection for a low-temperature solar organic Rankine cycle", Applied Thermal Engineering, vol. 29, no. 1112, pp. 2468-2476, 2009.

[15] G. Valencia, A. Fontalvo, Y. Cárdenas, J. Duarte and C. Isaza, "Energy and exergy analysis of different exhaust waste heat recovery systems 
for natural gas engine based on ORC",

Energies, vol. 12, no. 12, pp. 1-22, 2019.

[16] M. Yürüsoy and A. Keçebaş, "Advanced exergoenvironmental analyses and assessments of a real district heating system with geothermal energy", Applied Thermal Engineering, vol.113, pp. 449-459, 2017.

[17] F. Rizzi, C. Schio and S. Santarossa, "Hybrid ORC Waste Heat Recovery System and Solar Thermal Plant in Morocco", IEEE Transactions on Industry Applications, vol. 53, no. 1, pp. 1, 2016.

[18] J. Kalina, "Integrated biomass gasification combined cycle distributed generation plant with reciprocating gas engine and ORC", Applied Thermal Engineering, vol. 31, no. 14, pp. 2829-2840, 2011.

[19] S. Anvari, R. Khoshbakhti Saray, and K. Bahlouli, "Conventional and advanced exergetic and exergoeconomic analyses applied to a tri-generation cycle for heat, cold and power production", Energy, vol. 91, pp. 925-939, Nov. 2015.

[20] J. Bao and L. Zhao, "A review of working fluid and expander selections for organic Rankine cycle", Renewable and Sustainable Energy Reviews, vol. 24, no. Supplement C, pp. 325342, 2013.

[21] U. Drescher and D. Brüggemann, "Fluid selection for the Organic Rankine Cycle (ORC) in biomass power and heat plants", Applied Thermal Engineering, vol. 27, no. 1, pp. 223228, 2007.

[22] P. J. Mago, L. M. Chamra, K. Srinivasan and C. Somayaji, "An examination of regenerative organic Rankine cycles using dry fluids", Applied Thermal Engineering, vol. 28, no. 8, pp. 998-1007, 2008.

[23] G. Kosmadakis, D. Manolakos, S. Kyritsis and G. Papadakis, "Comparative thermodynamic study of refrigerants to select the best for use in the high-temperature stage of a two-stage organic Rankine cycle for RO desalination", Desalination, vol. 243, no. 1, pp. 74-94, 2009.
[24] B. F. Tchanche, G. Papadakis, G. Lambrinos and A. Frangoudakis, "Fluid selection for a low-temperature solar organic Rankine cycle", Applied Thermal Engineering, vol. 29, no. 1112, pp. 2468-2476, 2009.

[25] I. Vaja and A. Gambarotta, "Internal Combustion Engine (ICE) bottoming with Organic Rankine Cycles (ORCs)", Energy, vol. 35, no. 2, pp. 1084-1093, 2010.

[26] W. Mingshan, F. Jinli, M. Chaochen and D. S. Noman, "Waste heat recovery from heavyduty diesel engine exhaust gases by medium temperature ORC system", Science China Technological Sciences, vol. 54, no. 10, pp. 2746-2753, 2011.

[27] H. Tian, G. Shu, H. Wei, X. Liang and L. Liu, "Fluids and parameters optimization for the organic Rankine cycles (ORCs) used in exhaust heat recovery of Internal Combustion Engine (ICE)", Energy, vol. 47, no. 1, pp. 125-136, 2012.

[28] T.-C. Hung, D.-S. Lee and J.-R. Lin, “An Innovative application of a solar storage wall combined with the low-temperature organic rankine cycle", International Journal of Photoenergy, no. 239137, pp. 1-12, 2014.

[29] V. Zare, "A comparative exergoeconomic analysis of different ORC configurations for binary geothermal power plants", Energy Conversion and Management, vol. 105, pp. 127-138, 2015.

[30] E. D. Kerme and J. Orfi, "Exergy-based thermodynamic analysis of solar driven organic Rankine cycle", Journal of Thermal Engineering, vol. 1, no. 5, pp. 192-202, 2015.

[31] F. Calise, M. D. D’Accadia, A. Macaluso, A. Piacentino and L. Vanoli, "Exergetic and exergoeconomic analysis of a novel hybrid solargeothermal polygeneration system producing energy and water", Energy Conversion and Management, vol. 115, no. 1-336, pp. 200-220, 2016.

[32] S. Karellas and K. Braimakis, "Energy-exergy analysis and economic investigation of a cogeneration and trigeneration $\mathrm{ORC}-\mathrm{VCC}$ hybrid 
system utilizing biomass fuel and solar power", Energy Conversion and Management, vol. 107, no. 1-122, pp. 103$113,2016$.

[33] E. Akrami, A. Chitsaz, H. Nami and S. M. S. Mahmoudi, "Energetic and exergoeconomic assessment of a multi-generation energy system based on indirect use of geothermal energy", Energy, vol. 124, no. 1, pp. 625-639, 2017.

[34] M. Zhao, M. Wei, G. Tian and P. Song, "Simulation of effects of ORC system installation on heavy duty truck", Applied Thermal Engineering, vol. 128, no. 75, pp. 1322-1330, 2018.
[35] "Ormat technologies - Global Projects" [Online]. Available: https:// www.ormat.com/en/projects/all/main/? Country $=$ USA \&Seg $=0 \& \mathrm{Tech}=8$.

[36] "Turboden: Products for Combined Heat and Power (CHP)", [Online]. Available: https:// www.turboden.com/case-histories?countries= \&applications $=1053 \&$ power $=\#$ filters.

[37] R. Saidur, M. Rezaei, W. K. Muzammil, M. H. Hassan, S. Paria and M. Hasanuzzaman, "Technologies to recover exhaust heat from internal combustion engines", Renewable and Sustainable Energy Reviews, vol. 16, no. 8, pp. 5649-5659, 2012. 